\title{
Association of increased platelet distribution width and red cell distribution width with recurrent pregnancy loss
}

\author{
Rajani Meena*, Mohan Lal Meena, Priyanka Meena, Renu Meena
}

\begin{abstract}
Department of Obstetrics and Gynecology, Sawai Man Singh Medical College and Attached Group of Hospitals, Jaipur, Rajasthan, India
\end{abstract}

Received: 09 January 2017

Accepted: 08 February 2017

\author{
*Correspondence: \\ Dr. Rajani Meena, \\ E-mail: rajnimeena308@gmail.com
}

Copyright: (C) the author(s), publisher and licensee Medip Academy. This is an open-access article distributed under the terms of the Creative Commons Attribution Non-Commercial License, which permits unrestricted non-commercial use, distribution, and reproduction in any medium, provided the original work is properly cited.

\begin{abstract}
Background: Recurrent pregnancy loss is defined as three or more consecutive pregnancy losses at or less than 20 weeks of gestation or with a fetal weight less than 500 grams. The aim was to compare platelet distribution width and red cell distribution width between pregnant women with a history of recurrent pregnancy loss and pregnant women without a history of pregnancy loss.

Methods: This was a prospective study to the evaluation of 70 pregnant women with a history of recurrent pregnancy loss and 70 pregnant women without a history of pregnancy loss in the first trimester.

Results: When compared pregnant women with a history of recurrent pregnancy loss and 70 pregnant women without a history of pregnancy loss, the pregnant women with a history of recurrent pregnancy loss had significantly higher platelet distribution width and red cell distribution width $(\mathrm{p} \leq 0.001$ for both). There was no statistically significant difference between the two groups in terms of age, BMI, Hemoglobin, TLC, hematocrit, platelecrit, mean corpuscular volume, mean corpuscular haemoglobin, mean corpuscular haemoglobin concentration $(\mathrm{p}>0.05)$.

Conclusions: An increased platelet distribution width and red cell distribution width with recurrent pregnancy loss.
\end{abstract}

Keywords: Platelet distribution width, Recurrent pregnancy loss, Red cell distribution width

\section{INTRODUCTION}

Recurrent pregnancy loss is defined as three or more consecutive pregnancy losses at or less than 20 weeks of gestation or with a fetal weight less than 500 grams. ${ }^{1}$ The American society for reproductive medicine (2008) proposed that recurrent pregnancy loss is defined as two or more failed clinical pregnancies confirmed by either sonographic or histopathological examination. ${ }^{1}$ Recurrent pregnancy loss affects between 1 in 300 and 1 in 100 couples. ${ }^{2}$ The aetiology of recurrent pregnancy loss is multifactorial and include uterine anomalies, endocrinological disorders, immunological causes, infection, chromosomal abnormalities and maternal autoimmune diseases. However, the underlying cause cannot be clarified in $50-60 \%$ of all recurrent miscarriages. ${ }^{3,4}$ Pregnancy causes many alterations in hemostatic balance and thus leads to a tendency towards thrombophilia. Such a tendency is considered as a mechanism that compensates for the hemostatic challenge of delivery. The natural inclination towards thrombophilia in pregnancy is due to the increase in several clotting factors, including factor I, factor VII, factor VIII and von Willebrand. Moreover other markers reflecting hypercoagulability (such as D-dimer and/or prothrombin fragment) are increased during pregnancy.., 6 Different polymorphisms of thrombophilic disorders are diagnosed in up to $40 \%$ of women who have experienced recurrent miscarriages. However, this association depends on the type of thrombophilic disorder and the gestational age at which fetal loss occurs. Thrombophilia is related to several biological markers that reflect either coagulation activation (such as prothrombin fragment and thrombin-antithrombin complex) or platelet activation 
(such as $\beta$ thrombomodulin or soluble platelet $\mathrm{P}$ selection). ${ }^{8,9}$ Thrombophilia refers to the qualitative failure of the physiological coagulation inhibitors. Either the qualitative or the quantitative impairment of physiological coagulation inhibitors results in a procoagulatory imbalance which eventually leads to a condition of compensated coagulopathy. This chronic state of coagulation is associated with an enhancement in platelet activation. ${ }^{10}$ The enhancement in platelet activation causes the discoid platelets to become more spherical and to acquire pseudopodia. Such an alteration in platelet shape helps the platelets to obtain a larger surface. ${ }^{11}$ Platelet distribution width (PDW) due to platelet activation, resulting from platelet swelling and pseudopodia formation.

Large platelets are metabolically and enzymatically more active than small platelets. That is, large platelets are capable of producing larger amounts of thromboxane A2 and $\beta$-thromboglobulin, which is associated with an increase in platelet size, which is further related to increased platelet aggregation and enhanced expression of adhesion molecules. ${ }^{11-13}$ Anisocytosis may occur as erythrocytes and thrombocytes undergo consumption due to underlying inflammation and thromboembolism. PDW and RDW might be regarded as biological markers that would reflect moderate hypercoagulability. Thrombophilias are inherited or acquired conditions which predispose an individual to thromboembolism.

Red cell distribution width is a red cell parameter that measures the variability of red cell volume/size (anisocytosis). Red cell distribution width can be reported statistically as RDW-CV (coefficient of variation) or RDW-SD (standard deviation). RDW-SD is an actual measurement of the width of the erythrocyte distribution curve (measured at a relative height of $20 \%$ above the baseline). Reference range: $39-46$ fL. ${ }^{14,15} \mathrm{RDW}-\mathrm{CV}$ is calculated from standard deviation and MCV. RDW-CV :1SD/MCV x 100, reference range :11.6-14.6\%.

\section{Reference range}

11.6-14.6\% platelet distribution width is an indicator of variation in the size of platelet which may be a sign of activation of platelets. PDW is a simple, practical and more specific marker of platelet activation. An increased PDW is an indication for the anisocytosis of platelets. Standard PDW ranges from 9 to $14 \mathrm{fL} .{ }^{16}$

\section{METHODS}

This study comprises patients who attended department of Obstetrics and Gynaecology, SMS medical college and associated hospitals, Jaipur, Rajasthan, India between February 2015 and December 2016. This was a hospital based comparative study between first-trimester pregnant women with a history of recurrent pregnancy losses (case) and without a history of pregnancy loss (control). A woman who had experienced recurrent pregnancy loss due to uterine anomalies, diabetes mellitus and thyroid disease were excluded.

All eligible patients fulfilling inclusion criteria will be explained about nature and purpose of the study. After taking their informed written consent, detail history, the general and systemic examination will be done. Patient's samples will be collected for routine laboratory examination along with sample for RDW and PDW in an EDTA vial from antecubital vein puncture. Red cell distribution width and platelet distribution width will be measured using full automated 5/6 parts haematology analyser. Collected samples will be sent to a designated lab of our hospital and reports will be procured personally.

\section{Statistical analysis}

Continuous variables will be summarised as mean and SD while nominal/categorical variables as percentages. Z-test will be used for analysis of continuous variables and Karl Pearson's correlation coefficient will be used for find out the correlation between two variables. Mini tab software will be used for all statistical calculation.

\section{RESULTS}

The study comprised a total of 70 women who had a history of recurrent pregnancy loss (cases) and 70 pregnant women without a history of recurrent pregnancy loss (controls). The mean age of cases was 27.0 \pm 5.2 and controls were $27.1 \pm 5.2$ and mean body mass index (BMI)

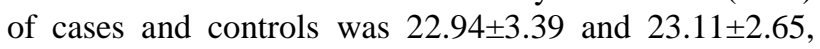
respectively.

Table 1: Comparison of mean age, BMI and blood pressure of patients between the groups.

\begin{tabular}{|llll|}
\hline Parameters & Mean \pm SD & \multicolumn{2}{l|}{ P-value } \\
\hline & Cases & Controls & \\
\hline Age (years) & $26.94 \pm 4.15$ & $25.77 \pm 3.93$ & $>0.05$ \\
\hline BMI & $20.51 \pm 2.79$ & $20.02 \pm 2.70$ & $>0.05$ \\
\hline Systolic BP & $114 \pm 5.92$ & $113 \pm 5.56$ & $>0.05$ \\
\hline Diastolic BP & $73.90 \pm 5.91$ & $72.40 \pm 6.64$ & $>0.05$ \\
\hline
\end{tabular}

$\mathrm{P}<0.05$ was accepted to be statistically significant.

There was no statistically significant difference between the two groups in terms of age, BMI, haemoglobin, TLC, hematocrit, mean corpuscular volume, mean corpuscular haemoglobin, mean corpuscular haemoglobin concentration, platelecrit ( $\mathrm{p}>0.05)$.

The pregnant women with a history of recurrent pregnancy loss had significantly higher RDW and PDW $(\mathrm{P}=<0.001)$. The comparison of mean age, BMI, systolic blood pressure, diastolic blood pressure values of patients between the groups in Table 1. The comparison of blood parameters of patients between the groups in shown in Table 2 . 
Table 2: Comparison of blood parameters of patients between the groups.

\begin{tabular}{|llll|}
\hline Parameters & Mean \pm SD & & P-value \\
\hline & Cases & Controls & \\
\hline Hb. $(\mathrm{g} / \mathrm{dl})$ & $11.27 \pm 1.53$ & $11.07 \pm 1.30$ & $>0.05$ \\
\hline TLC $\left(10^{3} / \mathrm{ul}\right)$ & $9.28 \pm 2.3$ & $9.1 \pm 1.5$ & $>0.05$ \\
\hline $\mathrm{MCV}(\mathrm{fl})$ & $85.49 \pm 7.75$ & $82.30 \pm 11.80$ & $>0.05$ \\
\hline $\mathrm{MCH}(\mathrm{pg})$ & $27.10 \pm 3.14$ & $27.71 \pm 6.90$ & $>0.05$ \\
\hline MCHC $(\mathrm{g} / \mathrm{dl})$ & $31.62 \pm 1.40$ & $31.94 \pm 1.28$ & $>0.05$ \\
\hline Plateletcrit $(\%)$ & $0.26 \pm 0.08$ & $0.26 \pm 0.06$ & $>0.05$ \\
\hline Hematocrit & $35.54 \pm 4.15$ & $34.19 \pm 4.47$ & $>0.05$ \\
\hline RDW-SD & $48.55 \pm 8.21$ & $42.64 \pm 6.63$ & $<0.001$ \\
\hline RDW-CV & $16.33 \pm 3.34$ & $14.86 \pm 2.12$ & $<0.001$ \\
\hline PDW & $15.90 \pm 2.89$ & $12.05 \pm 2.60$ & $<0.001$ \\
\hline
\end{tabular}

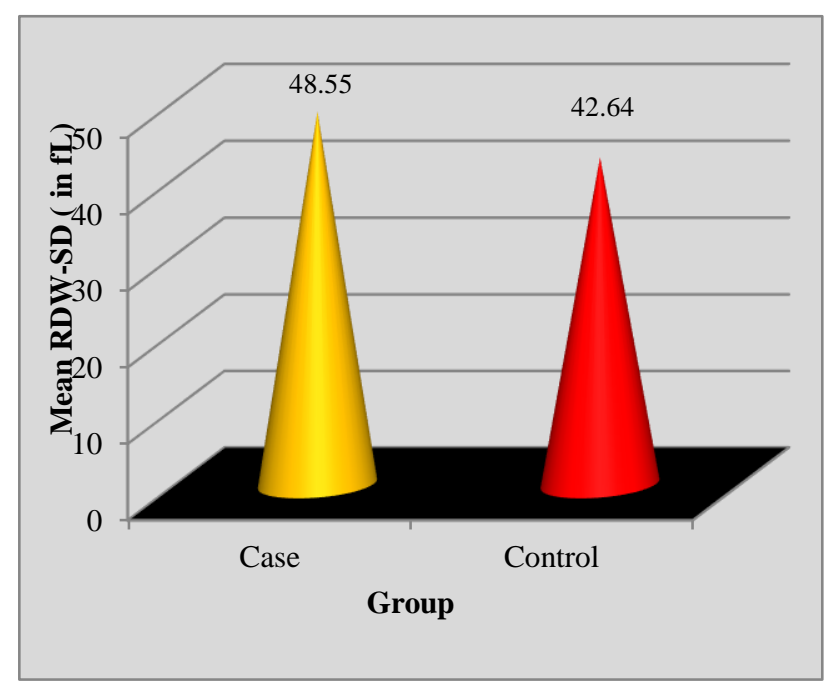

Figure 1: Mean RDW-SD of case and control group subjects.

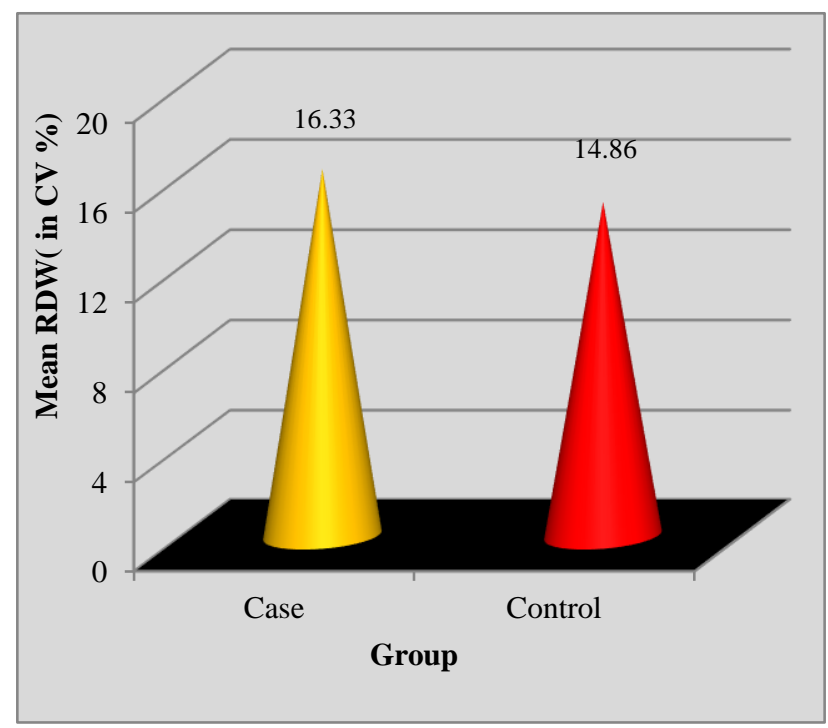

Figure 2: Mean RDW-CV of case and control group subjects.

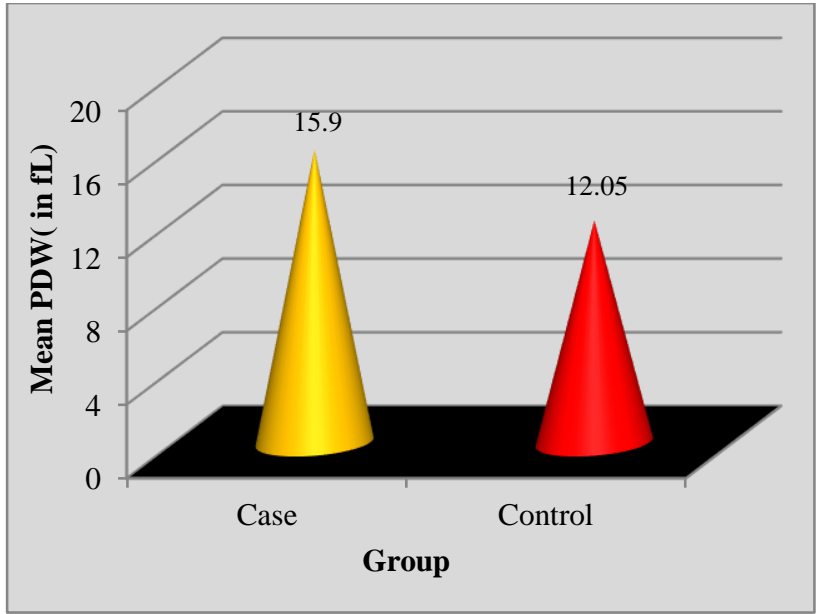

Figure 3: Mean PDW of case and control group subject.

\section{DISCUSSION}

Present study was a hospital based comparative analysis study done between first-trimester pregnant women with a history of recurrent pregnancy losses (cases) and without a history of pregnancy loss (controls) attending department of Obstetrics and Gynaecology SMS Medical College, Jaipur, Rajasthan, India.

In present study both groups were compared on the basis of age, religion, literacy, rural/urban, socioeconomic status, height, body weight and BMI ( $\mathrm{P}>0.05$ for each). There is no significant difference in the mean value of haemoglobin, total leukocyte count, hematocrit cases group when compared to control groups. Ahmet Uysal et al conducted a study showed that no statistically significant differences in haemoglobin, haematocrit and white blood cells count (WBC) between 2 groups $(\mathrm{p}>0.05$, respectively). ${ }^{17}$

In present study, no statistically significant difference was noticed in platelecrit between 2 groups. Sumerya et al conducted a study showed that no statistically significant differences in plateletcrit between the two groups $(\mathrm{p}>0.05){ }^{18}$

It was observed in our study that means RDW-SD and RDW-CV values of cases group were higher i.e. $48.55+8.21$ and $16.33+3.34$ than controls group i.e. $42.64 \pm 6.63$ and $16.33+3.34$ respectively. Mean PDW values of cases group were higher i.e. 15.90+2.89 than control group i.e. $12.05+2.60$. We observed that increased RDW and PDW was associated with recurrent pregnancy loss.

\section{CONCLUSION}

It is concluded from present study that thrombophilia has a significant role in the pathophysiology of recurrent pregnancy loss which leads to increase in RDW and PDW. Complete blood count is a simple test and can be 
performed easily at primary health centre level and early identification of high risk cases is possible so that patient can be timely referred to higher centres and early pregnancy loss can be prevented.

\section{ACKNOWLEDGEMENTS}

Authors would like to express my profound gratitude to all the participants for their co-operation and for their immense faith they reposed in me.

Funding: No funding sources

Conflict of interest: None declared

Ethical approval: The study was approved by the Institutional Ethics Committee

\section{REFERENCES}

1. Cunningham FG, Leveno KJ, Bloom SL, Hauth JC. Abortion. In: Williams Obstetrics. 24th Ed. McGraw-Hill Medical; 2010:358-9.

2. Berek JS, Abaid LN, Anderson JR, Aubuchon M. Recurrent pregnancy loss. In: Berek and Novak's Gynecology. 15th ed. Lippincott Williams and Wilkins; 2015:1190.

3. Christiansen OB, Nybo AAM, Bosch E. Evidencebased investigations and treatments of recurrent pregnancy loss. Fertil Steril. 2005;83:821-39.

4. Battinelli EM, Bauer KA. Thrombophilias in pregnancy. Hematol Oncol Clin North Am. 2011;25:323-33.

5. Colman-Brochu S. Deep vein thrombosis in pregnancy. MCN Am J Matern Child Nurs. 2004;29:186-92.

6. Robertson L, Wu O, Langhorne P. Thrombophilia in pregnancy: A systematic review. Br J Haematol. 2006;132:171-96.

7. D’Uva M, Di Micco P, Strina I, De Placido G. Recurrent pregnancy loss and thrombophilia. J Clin Med Res. 2010;2:18-22.

8. Gaussem P. Assessment of platelet function in man. Therapie. 2006;61:395-400.

9. Joly B, Barbay V, Borg JY, Le Cam-Duchez V. Comparison of markers of coagulation activation and thrombin generation test in uncomplicated pregnancies. Thromb Res. 2013;132:386-91.

10. Vagdatli E, Gounari E, Lazaridou E, Katsibourlia E, Tsikopoulou F, Labrianou I. Platelet distribution width: A simple, practical and specific marker of activation of coagulation. Hippokratia. 2010;14:2832.

11. Ntaios G, Gurer O, Faouzi M, Aubert C, Michel P. Hypertension is an independent predictor of mean platelet volume in patients with acute ischemic stroke. Intern Med J. 2011;41:691-5.

12. Chu SG, Becker RC, Berger PB. Mean platelet volume as a predictor of cardiovascular risk: A systematic review and meta-analysis. J Thromb Haemost. 2010;8:148-56.

13. Colkesen Y, Acil T, Abayli B. Mean platelet volume is elevated during paroxysmal atrial fibrillation: A marker of increased platelet activation? Blood Coagul Fibrinolysis. 2008;19:411-4.

14. Cholada Vejabhuti Curry,Eris B staros.Red cell distribution width. 2015. Available at: emedicine.medscape.com.

15. Curry CV, Staros EB. Mean corpuscular volumne. 2015. Available at: emedicine.medscape.com.

16. Aynioglu O, Isik H, Harma MI, Isik M, Kokturk F. Can Platelecrit be a marker for recurrent pregnancy loss? Clin Appl Thromb Hemostat. 2014;22(5):44752

17. Uysal RA, İncebıyık A, Hacıvelioğlu S, Gencer M, Güngör A, Çanakkale EC. Is There Any Relationship between Platelet Functions, Red Cell Distribution Width and Recurrent Pregnancy Loss? J Clin Anal Med. 2015;6(2):149-51.

18. Avcioğlu SN, Altinkaya SÖ, Küçük M. Sezer SD, Yüksel H. The Association between Platelet Indices and clinical parameters in recurrent pregnancy loss. Gynecol Obstet Reprod Med. 2014;20:146-9.

Cite this article as: Meena R, Meena ML, Meena P, Meena R. Association of increased platelet distribution width and red cell distribution width with recurrent pregnancy loss. Int J Reprod Contracept Obstet Gynecol 2017;6:1083-6. 